\title{
Functional Abdominal Pain Disorders in Children
}

\author{
Muzal Kadim \\ Division of Gastroentero-hepatology, Department of Child Health, Faculty of Medicine \\ Universitas Indonesia/Dr. Cipto Mangunkusomo National General Hospital, Jakarta
}

\begin{abstract}
Corresponding author:
Muzal Kadim. Division of Gastroentero-hepatology, Department of Child Health, Dr. Cipto Mangunkusomo National General Hospital. Jl. Diponegoro No. 71 Jakarta Indonesia. Phone: +62-21-31930373; facsimile:+62-21-3912477.E-mail:muzalk@yahoo.com
\end{abstract}

\begin{abstract}
Diagnostic criteria for functional abdominal pain has developed in the last decade, from the Rome III criteria to the Rome IV criteria. The major change was in the phrase "abdominal pain related gastrointestinal disorders" to "functional abdominal pain disorders (FAPD)". According to Rome IV criteria, FAPD are divided into functional dyspepsia (FD), irritable bowel syndrome (IBS), abdominal migraine, and functional abdominal pain-not otherwise specified (FAP-NOS). In order to diagnose FAPD, it is important to pay attention to alarm signs that can indicate organic abnormalities. The pathophysiology of FAPD was a complex interaction between psychosocial, genetic, environmental and life experiences of children through the gut brain axis. The risk factors for functional abdominal pain in children include psychological factors including anxiety and depression, stress conditions, negative experiences, and socioeconomic status.
\end{abstract}

Keywords: functional abdominal pain disorders, Rome IV criteria, children

\section{ABSTRAK}

Kriteria diagnostik untuk sakit perut fungsional telah berkembang dalam dekade terakhir, dari kriteria Rome III hingga kriteria Rome IV. Perubahan besar terjadi dari frasa "abdominal pain related gastrointestinal disorders" menjadi "functional abdominal pain disorders (FAPD)". Menurut kriteria Rome IV, FAPD dibagi menjadi dispepsia fungsional, irritable bowel syndrome, migrain abdomen, dan nyeri perut fungsional tidak spesifik lainnya. Untuk mendiagnosis FAPD, penting untuk memperhatikan tanda bahaya yang dapat mengindikasikan kelainan organik. Patofisiologi FAPD merupakan interaksi yang kompleks antara psikososial, genetik, lingkungan dan pengalaman hidup anak melalui gut brain axis. Faktor risiko sakit perut fungsional pada anak meliputi faktor psikologis yang meliputi kecemasan dan depresi, kondisi stres, pengalaman negatif, dan status sosial ekonomi.

Kata kunci: functional abdominal pain disorders, kriteria Rome IV, anak

\section{INTRODUCTION}

Functional abdominal pain is one of the most common functional gastrointestinal disorders in children. Functional gastrointestinal disorder is defined as a recurrent gastrointestinal complaint characterized by no structural or biochemical abnormalities. The pathogenesis and pathophysiology are not known completely. ${ }^{1}$ The biopsychosocial model that connects homeostasis between gut and brain is the most accepted theory to explain today, by the absence of organic matter, but affects the interaction between the brain and the gastrointestinal tract. ${ }^{1,2}$ Functional 
gastrointestinal disorders are a common problems that occurs in children and the most common causes of children being brought to the doctor. ${ }^{3}$ In children, it is associated with low quality of life, psychological pressure, school absences, and poor school and physical activities. The prevalence of children over 4 years of age with functional gastrointestinal disorders ranges from $21.2-25 \%{ }^{4-9}$

Diagnostic criteria for functional abdominal pain has developed in the last decade, from the Rome III criteria to the Rome IV criteria. The process of developing the Rome IV criteria is related to findings about gut-brain interactions and the micro environment. One of the major differences between the two criteria is the change in the phrase "abdominal pain related gastrointestinal disorders" to "functional abdominal pain disorders (FAPD)". Not only have the phrases changed, but the classification and diagnostic criteria have also changed. ${ }^{10,11}$ According to Rome IV criteria, functional abdominal pain disorders are divided into functional dyspepsia (FD), irritable bowel syndrome (IBS), abdominal migraine, and functional abdominal pain-not otherwise specified (FAP-NOS) ${ }^{1}$

The prevalence of functional abdominal pain in children using the Rome III criteria has been widely studied. ${ }^{12}$ However, not many studies have used the Rome IV criteria. Changes in diagnostic criteria from Rome III to Rome IV resulted in changes in the prevalence of functional abdominal pain. A study in the United States found an increase in the prevalence of children with functional abdominal pain from 13.3\% using the Rome III criterion to $16.9 \%$ using the Rome IV criterion. ${ }^{4,10}$ In contrast, there was a decrease in the prevalence of children with functional abdominal pain in Colombia from $10.4 \%$ using the Rome III criteria to $8.2 \%$ using the Rome IV criteria. ${ }^{5}$ Research on functional abdominal pain in children in Indonesia was conducted using the Rome IV criteria with the result of $17.2 \% .^{13}$

Based on the Rome IV criteria, functional abdominal pain is defined as a complaint of abdominal pain that occurs at least once a week for 2 months. Complaints of pain can be episodic or continuous and there are no anatomical, inflammatory, metabolic, or malignant disorders that can explain these complaints. ${ }^{1}$ Diagnosis of functional abdominal pain requires clinicians to exclude metabolic, inflammatory and anatomic disorders in order to diagnose functional abdominal pain. Therefore, it is important to pay attention to alarm signs that can indicate organic abnormalities and can guide the clinician in selecting the appropriate diagnostic tool. Table 1 shows the alarm signs of children with chronic abdominal pain. ${ }^{11}$

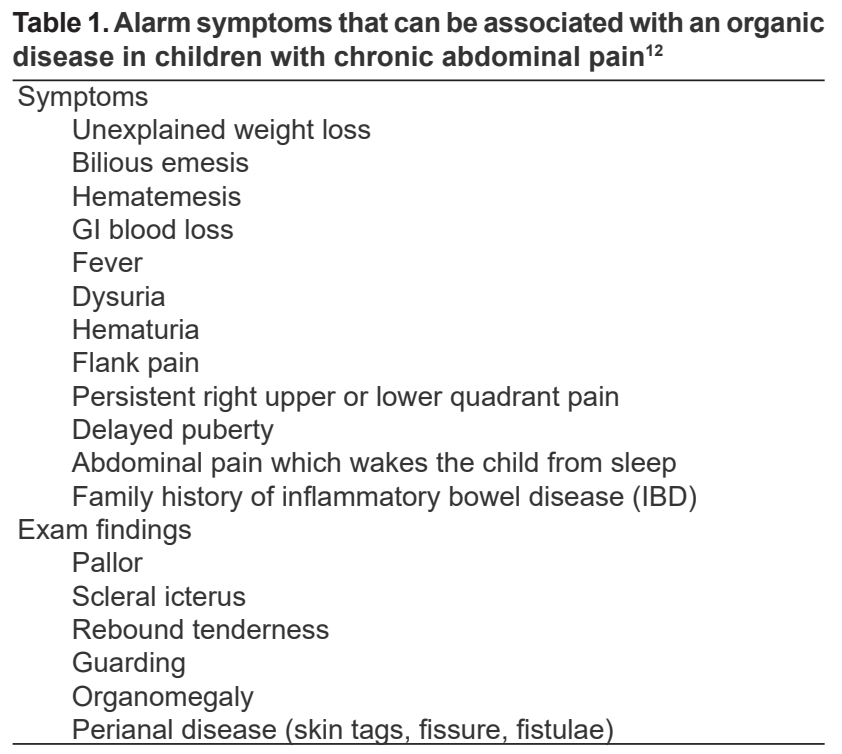

\section{PATHOPHYSIOLOGY}

The mechanism of functional abdominal pain in children is still unclear. Studies trying to find the exact cause and mechanism of functional abdominal pain in children are still few. The more organic pathology can be found along with the increasing advancement of science and medical diagnostic tools. Only cases that may be related to organic disorder, the case with the warning signs, requires further investigations. ${ }^{11}$

Perception of visceral pain pathways involving complex peripheral and central neural structures that encode, distribute, and modify the afferent stimuli. Several hypotheses made to explain the occurrence of functional abdominal pain, including visceral hyperalgesia, dysmotility, interaction of the 'brain-gut', inflammation, immunity, genetics, stress conditions, and biopsychosocial. ${ }^{11}$

Functional abdominal pain is a multifactorial disorder due to the complex interaction between psychosocial, genetic, environmental and life experiences of children through the gut brain axis. The bidirectional interaction of the gut brain is able to explain functional abdominal pain quite clearly. The brain constantly receives afferent impulses from the gastrointestinal tract and integrates them with various other interoceptive information about the body and the environment. The brain then sends feedback to various targets to maintain homeostasis. ${ }^{11}$

In a healthy child, most of the interoceptive information that reaches the brain is not consciously perceived. This interoceptive information is only used as input to the autonomic reflex pathways involved in 
homeostasis. In children with functional abdominal pain, the conscious perception of this interoceptive information or memories of the interoceptive becomes a perception of pain. Peripheral sensitization gives rise to a plasticity of the nociceptors to the stimulus so that stimulation is prolonged, particularly in inflammation or injury, resulting in a decrease in the threshold for pain stimulation. The main triggers for this primary sensitization process include bradykinin, histamine, serotonin, proteases, and cytokines. A history of gastrointestinal surgery, gastroenteritis, Henoch Schonlein purpura or cow's milk allergy can be the cause of this visceral hypersensitivity. ${ }^{11-16}$

\section{RISK FACTORS}

Current research mentions various things that are considered risk factors for functional abdominal pain in children. The risk factors for functional abdominal pain in children include psychological factors, stress conditions, negative experiences, and socioeconomic status. Psychological factors such as anxiety and depression are factors that are significantly associated with functional abdominal pain. Conversely, the presence of functional abdominal pain can cause depressive and anxiety symptoms in children. Various studies have shown an increased prevalence of functional abdominal pain in children with high stress levels. In addition, children with functional abdominal pain also had more traumatic or negative experiences, including the presence of a close relative who died, experienced domestic violence, parents lost their job, and history of being hospitalized. Families with low income and education levels have a percentage of children with functional abdominal pain, but various studies show this result is not statistically significant. The association between functional abdominal pain, anxiety, and depression in children and adolescents is well established. ${ }^{17-20}$

\section{CLINICAL EVALUATION}

A comprehensive history-taking and physical examination of children with abdominal pain are essential to rule out most organic causes. Alarm symptoms that might be related to organic causes are summarized in Table 1. Several studies evaluating the medical history of children with chronic abdominal pain have provided some evidence that frequency, severity, location and timing (postprandial or waking during night) of abdominal pain do not help distinguish between organic and functional. ${ }^{12}$

However, if the complaint does not improve with empiric therapy or there is a strong suspicion of organic disease, complete blood count, C-reactive protein, urinalysis and urine culture can be performed. Blood chemistry examination (liver function and kidney function), complete stool and stool culture, analysis of parasite feces, breath hydrogen test (BHT) can be done on a case by case basis. The investigation chosen is based on the child's main complaint, degree of functional disability and parental anxiety. Figure 1 shows a simple algorithm for determining the type of functional abdominal disorders. ${ }^{11}$

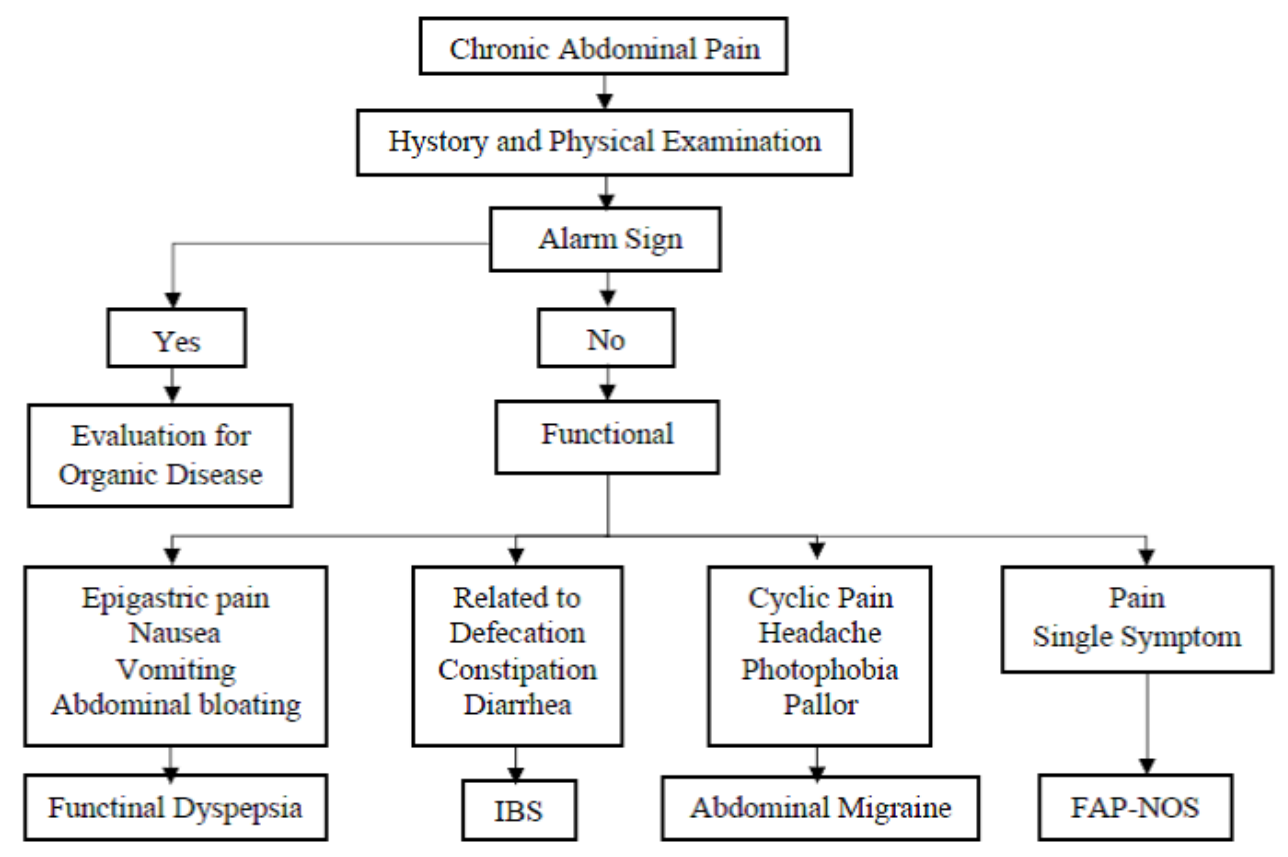

Figure 1. Diagnostic algorithm for childhood functional abdominal pain disorders ${ }^{11}$ 


\section{FUNCTIONAL DYSPEPSIA}

For at least 2 months before diagnosis, must include 1 or more of the following both or some symptoms at least 4 days per month: (1) Postprandial fullness; (2) Early satiation; (3) Epigastric pain or burning not associated with defecation; (4) After appropriate evaluation, the symptoms cannot be fully explained by another medical condition. ${ }^{1}$

The following subtypes are now adopted: (1) Postprandial distress syndrome includes bothersome postprandial fullness or early satiation that prevents finishing a regular meal. Supportive features include upper abdominal bloating, postprandial nausea, or excessive belching; (2) Epigastric pain syndrome, which includes all of the following: bothersome (severe enough to interfere with normal activities) pain or burning localized to the epigastrium. The pain is not generalized or localized to other abdominal or chest regions and is not relieved by defecation or passage of flatus. ${ }^{1}$

Functional dyspepsia associated with different underlying pathophysiologic disturbances associated with specific symptom patterns. Hypotheses include abnormalities of gastric motor function, visceral hypersensitivity due to central or peripheral sensitization, low-grade inflammation, and genetic predisposition. Impaired gastric accommodation, as determined by a decreased ability of the stomach to relax in response to a meal, has been demonstrated. Using electrogastrogram and gastric emptying studies, $50 \%$ of pediatric patients with FD had abnormal electrogastrogram and $47 \%$ slow gastric emptying. ${ }^{21-25}$

The role of endoscopy in pediatric FD is unclear, it was indicated in dyspeptic children with a family history of peptic ulcer disease or $\mathrm{H}$ pylori infection, children older than 10 years of age, when symptoms persist for $>6$ months, and if symptoms are severe enough to affect activities of daily living, including sleep. ${ }^{26}$

There are no adequately double-blind, placebocontrolled pediatric studies of FD treatment. Diet modifications such as avoiding fatty foods that can slow gastric emptying or avoiding foods and drinks that trigger intestinal gas production to prevent bloating. Proton pump inhibitor and histamine receptor antagonists can be given to patients with dominant symptoms of pain. Other therapies such as hypnotherapy and acupuncture can reduce symptoms of functional dyspepsia. Management of psychological factors that aggravate symptoms must also be done. ${ }^{27,28}$

\section{IRRITABLE BOWEL SYNDROME (IBS)}

IBS is a chronic functional disorder of the lower gastrointestinal tract, characterized by abdominal pain or discomfort, flatulence and erratic bowel habits. In addition, IBS is associated with a disturbed bowel pattern, of varying frequency and shape. At least 2 months before diagnosis, must include all of the following: (1) Abdominal pain at least 4 days per month associated with one or more of the following: (a) Related to defecation; (b) A change in frequency of stool; (c) A change in form (appearance) of stool; (2) In children with constipation, the pain does not resolve with resolution of the constipation (children in whom the pain resolves have functional constipation, not IBS); (3) After appropriate evaluation, the symptoms cannot be fully explained by another medical condition ${ }^{1}$

IBS is a biopsychosocial disorder that affects the brain-gut axis. Symptoms such as diarrhea, constipation, abdominal pain, psychosocial distress, reflect components of the involvement of the braingut axis. Visceral hypersensitivity is associated with children's psychological distress, such as anxiety, depression, impulsivity, and anger. Increased stress, anxiety, depression, and emotional problems are common in children with IBS. An increase in proinflammatory cytokines was also found in children after acute infective gastroenteritis (IBS post infection). ${ }^{28,29}$

A meta-analysis of IBS epidemiology in Asia states that the pooled prevalence of IBS in children and adolescents is $12.4 \%$ with prevalence in each country varies from $2.8 \%$ to $25.7 \%$. The prevalence of IBS varies because there are differences in geographical location, population, and diagnostic criteria used in each study. ${ }^{29-31}$ Only a few RCT studies have specifically examined the treatment of pediatric patients with IBS. Generally pediatric studies have put together other functional gastrointestinal disorders together. There are studies that support the usefulness of probiotics. ${ }^{32,33}$ One prospective, double-blind study in children reported the benefits of pepermint oil in reducing abdominal pain. ${ }^{34}$ Adouble-blind study of children with all IBS subtypes found the benefit of eliminating the intake of fermented oligosaccharides, disaccharides, monosaccharides, and polyols (FODMAPs). ${ }^{35}$

\section{ABDOMINAL MIGRAINE}

At least 6 months before diagnosis, must include all of the following occurring at least twice: (1) Paroxysmal episodes of intense, acute periumbilical, 
midline or diffuse abdominal pain lasting 1 hour or more (should be the most severe and distressing symptom); (2) Episodes are separated by weeks to months; (3) The pain is incapacitating and interferes with normal activities; (4) Stereotypical pattern and symptoms in the individual patient; (5) The pain is associated with 2 or more of the following (anorexia, nausea, vomiting, headache, photophobia, pallor); (6) After appropriate evaluation, the symptoms cannot be fully explained by another medical condition. ${ }^{1}$

The prevalence of abdominal migraine in children varies from $1-4 \%$, with a mean onset of age 7 years and a peak age of 10-12 years. ${ }^{4,5}$ Abdominal migraine, cyclic vomiting syndrome, and migraine headaches are thought to be an ongoing disorder. The etiology and pathogenesis of abdominal migraine is not fully understood. Children with abdominal migraines and classic migraines have the same triggers, such as stress, fatigue, and travel, as well as the same symptoms, such as anorexia, nausea, and vomiting, and the same relieving factors, such as rest and sleep. ${ }^{36}$

The treatment plan is determined by the frequency, severity, and impact of the abdominal migraine episodes on the child and family daily life. Prophylaxis with drugs such as amitriptyline, propranolol, pizotifen and cyproheptadine has been successful. ${ }^{37}$

\section{FUNCTIONAL ABDOMINAL PAIN-NOT OTHERWISE SPECIFIED}

At least 2 months before diagnosis, must be fulfilled at least 4 times per month and include all of the following: (1) Episodic or continuous abdominal pain that does not occur solely during physiologic events (eg, eating, menses); (2) Insufficient criteria for irritable bowel syndrome, functional dyspepsia, or abdominal migraine; (3) After appropriate evaluation, the abdominal pain cannot be fully explained by another medical condition ${ }^{1}$

It has been reported that children with FAP-NOS have lower antral contractions and slower emptying rates of a liquid meal compared with healthy controls, but the clinical significance of this finding is unclear. ${ }^{38}$ There is evidence for the association between psychological distress and chronic abdominal pain in children and adolescents. ${ }^{17-20}$ Chronic abdominal pain is associated with stressful life events, such as parental divorce, hospitalization, bullying, and childhood abuse. ${ }^{39,4}$

\section{CONCLUSION}

Functional abdominal pain disorders are the most common functional gastrointestinal disorders in children. Changes in the diagnostic criteria for functional abdominal pain from Rome III to Rome IV criteria resulted in changes in the prevalence of functional abdominal pain. Children with functional abdominal pain have gastrointestinal complaints associated with low quality of life, psychological pressure, school absences, and poor school and physical activities. It is important to pay attention to alarm signs that can indicate organic abnormalities to guide the clinician in selecting the appropriate diagnostic tool.

\section{REFERENCES}

1. Hyams JS, di Lorenzo C, Saps M, Shulman RJ, Staiano A, van Tilburg M. Childhood functional gastrointestinal disorders: child/adolescent. Gastroenterology 2016;150:1456-68.

2. Newton E, Schosheim A, Patel S, Chitkara DK, van Tilburg MAL. The role of psychological factors in pediatric functional abdominal pain disorders. Neurogastroenterol Motil 2019;31:e13538.

3. Rouster AS, Karpinski AC, Silver D, Monagas J, Hyman PE. Functional gastrointestinal disorders dominate pediatric gastroenterology outpatient practice. J Pediatr Gastroenterol Nutr 2016;62:847-51.

4. Robins SG, Keller C, Zweiner R, Hyman PE, Nurko $\mathrm{S}$, Saps M, et al. Prevalence of pediatric functional gastrointestinal disorders utilizing the Rome IV criteria. J Pediatr 2017;195:134-9.

5. Saps M, Velasco-Benitez CA, Langshaw AH, RamirezHernandez CR. Prevalence of functional gastrointestinal disorders in children and adolescents: comaparison between Rome III and Rome IV criteria. J Pediatr 2018;199:212-6.

6. Scarpato E, Kolacek S, Jojkic-Pavkov D, Konjik V, Zivkovic $\mathrm{N}$, Romen E, et al. Prevalence of functional gastrointestinal disorders in children and adolescents in the Mediterranean region of Europe. Clin Gastroenterol Hepatol 2018;16:870-6.

7. Lewis ML, Palsson OS, Whitehead WE, van Tilburg MAL. Prevalence of functional gastrointestinal disorders in children and adolescent. J Pediatr 2016;177:39-43.

8. Chogle A, Velasco-Benitez CA, Koppen IJ, Moreno JE, Ramirez-Hernandez CR, Saps M. A population-based study on the epidemiology of functional gastrointestinal disorders in young children. J Pediatr 2016;169:139-43.

9. Van Tilburg MA, Hyman PE, Walker L, Rouster A, Palsson OS, Kim SM, et al. Prevalence of functional gastrointestinal disorders in infants and toddlers. J Pediatr 2015;166:684-9.

10. Edwards T, Friesen C, Schurman JV. Classification of pediatric functional gastrointestinal disorders related to abdominal pain using Rome III vs. Rome IV criterions. BMC Gastroenterol 2018;18:41-6.

11. Sood MR, Matta SR. Approach to a child with functional abdominal pain. Indian J Pediatr 2016;6:1-7.

12. Korterink JJ, Diederen K, Benninga MA, Tabbers MM. Epidemiology of pediatric functional abdominal pain disorders: a meta-analysis. PLoS One 2015;10:e0126982. 
13. Oswari H, Alatas FS, Hegar B, Cheng W, Pramadyani A, Benninga MA, et al. Functional abdominal pain disorders in adolescents in Indonesia and their association with family related stress. BMC Pediatr 2019;19:342.

14. Mayer EA, Tillisch K. The brain-gut axis in abdominal pain syndromes. Annu Rev Med 2011;62:381-96.

15. Saps M, Pensabene L, Turco R, Staiano A, Cupuro D, di Lorenzo C. Rotavirus gastroenteritis: precursor of functional gastrointestinal disorders? J Pediatr Gastroenterol Nutr 2009;49:580-3.

16. Di Lorenzo C, Youssef NN, Sigurdsson L, Scharff L, Griffiths $\mathrm{J}$, Wald A. Visceral hyperalgesia in children with functional abdominal pain. J Pediatr 2001;139:838-43.

17. Campo JV, Bridge J, Ehmann M, Altman S, Lucas A, Birmaher $\mathrm{B}$, et al. Recurrent abdominal pain, anxiety, and depression in primary care. Pediatrics 2004;113:817-24.

18. Rutten JM, Benninga MA, Vlieger AM. IBS and FAPS in children:a comparison of psychological and clinical characteristics. J Pediatr Gastroenterol Nutr 2014;59:493-9.

19. Dorn LD, Campo JC, Thato S, Dahl RE, Lewin D, Chandra $\mathrm{R}$, et al. Psychological comorbidity and stress reactivity in children and adolescents with recurrent abdominal pain and anxiety disorders. J Am Acad Child Adolesc Psychiatry 2003;42:66-75.

20. Yacob D, Lorenzo CD, Bridge JA, Rosenstein PF, Onorato $\mathrm{M}$, Bravender T, et al. Prevalence of pain-predominant functional gastrointestinal disorders and somatic symptoms in patients with anxiety or depressive disorders. J Pediatr 2013;163:767-70.

21. Hoffman I, Vos R, Tack J. Assessment of gastric sensorimotor function in paediatric patients with unexplained dyspeptic symptoms and poor weight gain. Neurogastroenterol Motil 2007;19:173-9.

22. Schurman JV, Singh M, Singh V, Neilan N, Friesen CA. Symptoms and subtypes in pediatric functional dyspepsia: relation to mucosal inflammation and psychological functioning. J Pediatr Gastroenterol Nutr 2010;51:298-303.

23. Tack J, Masaoka T, Janssen P. Functional dyspepsia. Curr Opin Gastroenterol 2011;27:549-57.

24. Chitkara DK, Camilleri M, Zinsmeister AR, Burton D, ElYoussef M, Deborah Freese D, et al. Gastric sensory and motor dysfunction in adolescents with functional dyspepsia. J Pediatr 2005;146:500-5.

25. Friesen CA, Lin Z, Hyman PE, Andre L, Welchert E, Schurman JV, et al. Electrogastrography in pediatric functional dyspepsia: relationship to gastric emptying and symptom severity. J Pediatr Gastroenterol Nutr 2006;42:265-9.

26. Guariso G, Meneghel A, Dalla Pozza LV, Romeno C, Dall'Oglio $\mathrm{L}$, Lombardi $\mathrm{G}$, et al. Indications to upper gastrointestinal endoscopy in children with dyspepsia. J Pediatr Gastroenterol Nutr 2010;50:493-9.

27. Dehghani SM, Imanieh MH, Oboodi R, Mahmood H. The comparative study of the effectiveness of cimetidine, ranitidine, famotidine, and omeprazole in treatment of children with dyspepsia. ISRN Pediatr 2011;2011:219287.

28. Huertas-Ceballos A, Logan S, Bennett C, Macarthur C. Psychosocial interventions for recurrent abdominal pain (RAP) and irritable bowel syndrome (IBS) in childhood. Cochrane Database Syst Rev 2008;CD003014.

29. Devanarayana NM, Rajindrajith S. Irritable bowel syndrome in children: current knowledge, challenges and opportunities. World J Gastroenterol 2018;24:2211-35.
30. Devanarayana NM, Rajindrajith S, Pathmeswaran A, Abegunasekara C, Gunawardena NK, Benninga MA. Epidemiology of irritable bowel syndrome in children and adolescents in Asia. J Pediatr Gastroenterol Nutr 2015;60:792-8.

31. Gwee KA, Ghoshal UC, Chen M. Irritable bowel syndrome in Asia: pathogenesis, natural history, epidemiology, and management. J Gastroenterol Hepatol 2018;33:99-110.

32. Horvath A, Dziechciarz P, Szajewska H. Meta-analysis: Lactobacillus rhamnosus abdominal pain-related functional gastrointestinal disorders in childhood. Aliment Pharmacol Ther 2011;33:1302-10.

33. Guandalini S, Magazzu G, Chiaro A, Balestra VL, Nardo GD, Gopalanet S, et al. VSL\#3 improves symptoms in children with irritable bowel syndrome: a multicenter, randomized, placebo-controlled, double-blind, crossover study. J Pediatr Gastroenterol Nutr 2010;51:24-130.

34. Kline RM, Kline JJ, Palma D, Barbero GJ. Enteric-coated, pHdependent peppermint oil capsules for the treatment of irritable bowel syndrome in children. J Pediatr 2001;138:125128.

35. Chumpitazi BP, Hollister EB, Oezguen N, Tsai $\mathrm{CM}, \mathrm{McMeans} A \mathrm{R}$, Luna RA, et al. Gut microbiota influences low fermentable substrate diet efficacy in children with irritable bowel syndrome. Gut Microbes 2014;5:165-75.

36. Carson L, Lewis D, Tsou M, McGuire E, Surran B, Miller C, et al. Abdominal migraine: an under-diagnosed cause of recurrent abdominal pain in children. Headache 2011;51:707-12.

37. Worawattanakul M, Rhoads JM, Lichtman SN, Ulshen MH. Abdominal migraine: prophylactic treatment and followup. J Pediatr Gastroenterol Nutr 1999;28:37-40.

38. Devanarayana NM, Rajindrajith S, Rathnamalala N, Samaraweera S, Benninga MA. Delayed gastric emptying rates and impaired antral motility in children fulfilling Rome III criteria for functional abdominal pain. Neurogastroenterol Motil 2012;24:420-425;e207.

39. Boey CCM, Goh KL. The significance of life-events as contributing factors in childhood recurrent abdominal pain in an urban community in Malaysia. J Psychosom Res 2001;51:559-62.

40. Van Tilburg MA, Runyan DK, Zolotor AJ, Graham JC, Dubowidz H, Litrownik AJ, et al. Unexplained gastrointestinal symptoms after abuse in a prospective study of children at risk for abuse and neglect. Ann Fam Med 2010;8:134-40. 